\title{
UMA ANÁLISE SEMÂNTICA DOS OPERADORES ARGUMENTATIVOS EM ANÚNCIOS DA REVISTA VEJA ON-LINE
}

\section{A SEMANTIC ANALYSIS OF THE ARGUMENTATIVE OPERATORS IN VEJA ON-LINE MAGAZINE ADVERTISEMENTS}

\author{
Karina Morais Camargos ${ }^{1}$ \\ Juliana Bertucci Barbosa²
}

\begin{abstract}
Resumo: Essa pesquisa encontra-se no quadro teórico da semântica argumentativa, focalizando os operadores argumentativos em anúncios publicitários da revista Veja. Analisamos 20 operadores em 25 anúncios objetivando evidenciar suas características semânticas conforme classificação de Ducrot (1984) e Koch (2006). O estudo se justifica pelo fato de as escolas ensinarem apenas as funções sintáticas desses operadores, impedindo que os alunos desenvolvam uma visão abrangente em contato com esses elementos. As conclusões apontam que os operadores argumentativos carregam forte carga argumentativa direcionando o texto. O valor semântico desses operadores pode ou não variar, mas nenhum anúncio perdeu a função da argumentatividade.
\end{abstract}

Palavras-chave: Operadores argumentativos; anúncios publicitários; semântica; argumentação.

Abstract: This research is situated on the Argumentative Semantics theory, focusing on the argumentative operators in advertisements published on the Veja magazine. We analyzed 20 operators in 25 advertisements aiming to show their semantic features as the classification by Ducrot (1984) and Koch (2006). This study is important because at schools, students study just their syntactic functions, being prevented from developing a broader view when they face these elements. The findings indicate that the argumentative operators carry strong argumentative load directing the text. The semantic value of these operators may or not vary, but no announcement has missed the argumentativeness function.

Keywords: argumentative operators; advertisements published; semantics; argumentation

\section{Introdução}

No decorrer da história dos estudos da linguagem, muitos questionamentos e concepções se formaram sobre qual seria a função da linguagem: representação do pensamento, instrumento de comunicação ou lugar de interação ( $\mathrm{KOCH}, 2006$, p.07-08). Essas questões foram amplamente discutidas pelos estudiosos da língua(gem), porém, a

\footnotetext{
${ }^{1}$ Graduada em Letras, Licenciatura em Português e Inglês, pela Universidade Federal do Triângulo Mineiro.

2 Doutora em Linguística e Língua Portuguesa pela UNESP. Professora do Departamento de Linguística e Língua Portuguesa (DeLLP) da Universidade Federal do Triângulo Mineiro (UFTM).
} 
concepção mais aceita, da qual coadunamos, é a de que a linguagem é lugar de interação.

Seguindo essa concepção, acreditamos que ao interagirmos por meio da linguagem sempre temos objetivos, fins a serem atingidos. Essa característica inclui o objeto de estudo deste artigo, o anúncio publicitário. Os anúncios publicitários buscam interagir e agir sobre os consumidores, visando uma única ação esperada, a compra do produto. Nesse gênero textual, o locutor é sempre considerado, levando-se em conta diversos fatores como idade, classe social, escolaridade, dentre outros.

Dessa forma, a linguagem publicitária presente nos anúncios pretende levar o enunciatário à compra de um produto e, para atingir seu objetivo, faz uso de recursos linguísticos e visuais, sendo de fundamental importância os mecanismos semânticoargumentativos, utilizados para orientar o locutor para uma determinada conclusão. Nesse contexto publicitário, a questão da argumentação é de extrema importância, pois, uma argumentação bem sucedida é o primeiro passo para o sucesso do produto. Para que esse fim seja alcançado, muitos recursos, verbais (linguísticos) e não-verbais, são utilizados.

Dentre os procedimentos linguísticos colaboradores da argumentatividade, de acordo com Koch (2004, p.30), com base na Semântica Argumentativa, de Oswald Ducrot, (1874), temos os operadores argumentativos. Esses elementos têm por função indicar (mostrar) a força argumentativa dos enunciados, a direção (sentido) para o qual apontam.

Partindo dessa teoria, o principal objetivo deste artigo é fazer um levantamento descritivo de quais são os operadores argumentativos mais empregados em anúncios publicitários extraídos da revista on-line Veja publicada no período de outubro de 2011 a fevereiro de 2012. Buscamos ainda evidenciar, seguindo as definições de Ducrot (1987) e Koch (2006), as características semânticas dos operadores encontrados.

Cabe ressaltar que um estudo semântico dessas formas - os operadores argumentativos - além de colaborar com os estudos descritivos sobre o Português Brasileiro (PB) -, justifica-se também por evidenciar as características semânticas, e não apenas sintáticas, como focalizam a maioria das escolas, desses elementos linguísticos.

Antes de apresentarmos e discutirmos a análise dos operadores argumentativos encontrados nos anúncios, inicialmente, neste artigo, realizamos uma sucinta discussão 
de como esses operadores são definidos em gramáticas e em estudos linguísticos. Em seguida, além de apontarmos alguns resultados de pesquisas linguísticas já feitas sobre o assunto, apresentamos os procedimentos metodológicos e a montagem do corpus utilizados nesta pesquisa.

\section{Argumentação e Operadores argumentativos}

Para Ducrot (1987), argumentar é apresentar A em favor de uma conclusão C, apresentar A como devendo levar o destinatário a concluir $\mathrm{C}$. O autor considera este ato como um ato linguístico fundamental e afirma que a argumentatividade se acha inscrita sistematicamente na língua. $O$ uso da linguagem é, portanto, inerentemente argumentativo.

Sendo assim, tem-se o reconhecimento de um valor retórico dos elementos gramaticais. Para Koch (2008), ao se reconhecer tal valor retórico, faz-se necessário admitir a existência de enunciados que orientam o interlocutor para certos tipos de conclusão, com exclusão de outros. A linguista demonstra que a gramática de cada língua possui palavras responsáveis por uma relação precisa de enunciados que são os operadores argumentativos ou discursivos. Tais operadores são constituídos de conectivos e vocábulos. Os conectivos são considerados tradicionalmente como elementos meramente relacionais, já os segundos, os vocábulos ou palavras lexicais, de acordo com a NGB, não se enquadram em nenhuma das dez classes gramaticais.

Retomando os preceitos de Ducrot, temos ainda, em relação aos operadores argumentativos, a noção de escala argumentativa. Nas palavras de Koch (2008) temos uma escala argumentativa quando dois ou mais argumentos orientados no mesmo sentido, isto é, para uma mesma conclusão, constituem uma classe argumentativa. Desnecessário dizer que são esses operadores os responsáveis pelo encadeamento dos argumentos numa escala. São eles que direcionam o argumento para essa ou aquela conclusão.

Portanto, podemos afirmar que grande parte da força argumentativa de um texto está na dependência desses operadores argumentativos. Daí a importância de um estudo que enfoque sua utilização, sobretudo em determinados gêneros textuais - como os anúncios publicitários - que vivem do seu poder de atuar sobre o outro para obter dele determinadas reações (verbais ou não-verbais). É o que pretendemos fazer neste artigo, 
examinando anúncios publicitários presentes na revista on-line Veja. Esta revista é semanal e de cunho informativo, direcionada ao público em geral, com tendências a focalizar um leitor mais culto, mais elitizado.

\subsection{Os operadores argumentativos nas gramáticas}

Ao tratar de determinados elementos da língua, Ducrot (1987) observou que eles tinham o poder de direcionar o(s) argumento(s) de um enunciado para uma conclusão desejada. Conseguintemente, como vimos na seção anterior, o autor chamou esses elementos de operadores argumentativos, analisando-os por meio das noções de classe e escala argumentativa. Em ambas as noções, temos mais de um argumento que apontam para uma mesma conclusão (por meio de um operador argumentativo), na escala argumentativa, porém, temos uma gradação de força dos argumentos que compõe os enunciados. Ao decorrer da análise, essas noções serão melhor esclarecidas e exemplificadas.

Se o linguista, por um lado, trata os operadores argumentativos como parte essencial do processo de argumentação, por outro, as gramáticas normativas muitas vezes, apenas os estudam como meros conectores, classificando-os de acordo com o "sentido" que eles proporcionam às sentenças.

Ao consultar três gramáticas normativas (BECHARA, 2007; CEGALLA, 2010; CUNHA, CINTRA, 2008), verificamos diversos pontos em comum em relação aos operadores argumentativos. Um dos pontos é que nenhuma das três gramáticas faz referência a esses conectivos como operadores argumentativos. Apenas em consulta a uma gramática descritiva, de Neves (2011), é que pudemos observar a argumentatividade como uma das funções de alguns conectores.

As gramáticas normativas consultadas apresentam os operadores argumentativos, de um modo geral, como conjunções, advérbios, palavras denotativas, dentre outros. Inicialmente, elas apresentam uma explicação da função do elemento e depois é feita uma classificação. Tomemos como exemplo o operador argumentativo mas. Todas as gramáticas normativas consultadas colocam o mas no grupo das conjunções. Antes, porém, costuma-se definir o que é conjunção, o que ocorreu nas três gramáticas normativas consultadas: "Vocábulos gramaticais que servem para relacionar duas orações ou dois termos semelhantes da mesma oração". Em seguida a esta definição, 
aparece a classificação dessa conjunção em um subgrupo que expressaria o "sentido". O mas é, para essas gramáticas, uma conjunção coordenada adversativa, ou seja, que expressa relação de desigualdade entre os segmentos os quais une. Além disso, a maioria dessas gramáticas revela, além de uma explicação simplista, outras funções semânticas desse conectivo, tais como: exprimir ideia de restrição, de retificação, de atenuação ou compensação, de adição, dentre outras.

Entretanto, na Gramática de usos do português, de Neves (2011), como o próprio título afirma, por ser uma gramática descritiva baseada nos usos dos elementos da língua, encontramos uma abordagem mais ampla sobre os operadores argumentativos. Nessa gramática, os operadores aparecem com a propriedade de funcionarem para organizar a informação e estruturar a argumentação (NEVES, 2011, p.757), aproximando-se dos preceitos de Ducrot (1987). Por isso, essa gramática descritiva traz diversos exemplos de como os operadores funcionam nos enunciados, direcionando os argumentos. Por exemplo, citamos novamente o caso do mas:

"Longo, mas lido com voz clara e sem hesitações, o discurso no Congresso arrancou aplausos em várias ocasiões."

- Argumento negativo: longo (cansativo)

- mas (em compensação)

- Argumento positivo: lido com voz clara e sem hesitações

- Conclusão $\rightarrow$ O discurso não foi cansativo (inclusive arrancou aplausos em várias ocasiões). O mas proporciona força ao segundo elemento, levando a conclusão a favor do mesmo. (Neves, 2011 p.760)

O fragmento acima ilustra, por meio da partícula mas, os valores semânticos que os operadores argumentativos podem carregar. Veremos essa questão mais detalhadamente durante a análise dos anúncios publicitários, ocasião em que será focalizada somente a função argumentativa e semântica dos operadores.

É importante destacar ainda que o que observamos com o "mas" nas gramáticas normativas, acontece também com as demais conjunções, advérbios, palavras denotativas e com algumas preposições chamadas de "acidentais". É dada a definição da classe de palavra e a classificação. Resumidamente, de acordo com as gramáticas normativas consultadas, o advérbio é uma palavra que modifica o sentido do verbo, do adjetivo e do próprio advérbio, podendo ainda modificar a oração inteira. Já na Gramática de usos do português encontramos uma definição mais aceitável, acerca dos advérbios, 
levando-se em conta seu valor semântico. Nessa gramática de usos, Neves (2011) afirma que os advérbios são fóricos ${ }^{3}$, isto é, remetem a algum outro elemento, dentro ou fora do enunciado: (por exemplo, Este filme de hoje é apavorante, não presta pra crianças de tua idade). As tabelas abaixo I e II, adaptadas de Neves (2011), explicitam os valores semânticos de alguns advérbios:

Tabela I $^{4}$ : Advérbios que se referem a um momento ou período determinado da enunciação ou de outro ponto do enunciado (fóricos)

\begin{tabular}{|c|c|c|c|}
\hline & $\begin{array}{c}\text { Tempo } \\
\text { cronológico }\end{array}$ & Tempo não cronológico & Exemplo \\
\hline HOJE & neste dia & Indica "na época atual". & $\begin{array}{l}\text { Ex.1: Até HOJE, um ano depois de concluídas as } \\
\text { pesquisas, não apareceu ninguém interessado } \\
\text { na utilização industrial do processo. (hoje = neste } \\
\text { dia) } \\
\text { Ex2: O perigo é HOJE muito maior do que } \\
\text { naquela ocasião. (hoje=na época atual) }\end{array}$ \\
\hline AGORA & & $\begin{array}{l}\text { Indica: neste momento, na } \\
\text { época atual, neste } \\
\text { momento ou período, } \\
\text { prolongando-se para o } \\
\text { período imediatamente } \\
\text { seguinte a este, no } \\
\text { momento/período } \\
\text { imediatamente anterior a } \\
\text { este, nos últimos tempos }\end{array}$ & $\begin{array}{l}\text { Ex1: Só AGORA é que a senhora se lembrou } \\
\text { disso? } \\
\text { Ex2: Estava dizendo um matuto, na venda, que } \\
\text { Aparício anda AGORA com mais de duzentos } \\
\text { homens. }\end{array}$ \\
\hline
\end{tabular}

Fonte: Neves (2011, p.265 /adaptado)

Tabela II : Advérbios em uma Situação relativa (a situação pode ser referida a um momento da enunciação ou do enunciado - fóricos)

\begin{tabular}{|l|l|l|}
\hline JÁ & $\begin{array}{l}\text { Neste/nesse/naquele momento } \\
\text { ou período, considerado como } \\
\text { precedente de outro (s) }\end{array}$ & $\begin{array}{l}\text { Ex: JÁ o sol da manhã espalhava- } \\
\text { se sobre o sertão florido. }\end{array}$ \\
\hline AINDA & $\begin{array}{l}\text { Em /até este/esse/aquele } \\
\text { momento ou período considerado } \\
\text { como subsequente a outro (s) }\end{array}$ & $\begin{array}{l}\text { Ex: Você AINDA não ouviu nada, } \\
\text { sua miserável! }\end{array}$ \\
\hline
\end{tabular}

Fonte: Neves (2011, p.268 /adaptado)

Analisando as Tabelas I e II acima, podemos observar que os advérbios têm um papel maior do que modificar o verbo, advérbio ou adjetivo. Eles possuem um forte valor semântico, que dependendo do contexto em que são inseridos, seu sentido é também

\footnotetext{
3 Os advérbios fóricos, para Neves, têm natureza pronominal, comportando-se como proformas nominais, o que lhes permite, aliás, funcionar como argumentos.

4 Extraímos de Neves (2011) apenas os advérbios equivalentes aos operadores argumentativos presentes no corpus da nossa pesquisa.

Idem nota anterior.
} 
alterado. A simples questão do tempo cronológico e não cronológico aponta para esse valor semântico. $\mathrm{Na}$ análise dos nossos dados, veremos que além do papel de marcador de tempo (no caso dos advérbios de tempo), será acrescido a esses advérbios um valor argumentativo, decisivo para direcionar determinadas conclusões.

\subsection{Os operadores argumentativos}

A Semântica Argumentativa recupera os operadores argumentativos por acreditar que eles determinam o valor argumentativo dos enunciados; constituem-se, pois, importantes marcas linguísticas para a enunciação - evento único de produção do enunciado que jamais se repete $(\mathrm{KOCH}, 2008)$.

Segundo Koch (2006, p.31-39), baseada em Ducrot (1987), existem vários grupos de operadores argumentativos, dentre eles, destacam-se nove tipos:

a) Operadores que assinalam o argumento mais forte dentro de uma escala que direciona para determinada conclusão: (até, mesmo,até mesmo, inclusive);

b) Operadores que somam argumentos a favor de uma mesma conclusão: (e, também, ainda, nem (=e não), não só... mas também, além de..., além disso..., a par de...,etc.)

c) Operadores que introduzem uma conclusão relacionada a um argumento apresentado anteriormente: (portanto, logo, por conseguinte, pois, etc.);

d) Operadores que permitem introduzir argumentos alternativos e levam a conclusões opostas ou diferentes: (ou, ou então, quer... quer, seja... seja, etc.);

e) Operadores que estabelecem relações de comparação entre elementos, com vistas a uma dada conclusão: (mais que, menos que, tão... como, etc.);

f) Operadores que introduzem uma justificativa ou explicação relativa ao enunciado anterior: (porque, já que, pois, etc.);

g) Operadores que contrapõem argumentos orientados para conclusões contrárias: mas (porém, contudo, no entanto, etc.), embora (ainda que, posto que, apesar (de que), etc.);

h) Operadores que têm por função introduzir no enunciado conteúdos pressupostos: (já, ainda, agora, etc.);

i) Operadores que se distribuem em escalas opostas, isto é, um deles funciona numa escala orientada para a afirmação total e o outro, para a negação total.

Após a descrição destes operadores, podemos observar que a interação social por meio da língua caracteriza-se fundamentalmente pela argumentatividade, que se revela 
por meio de mecanismos da própria língua, mecanismos estes que permitem indicar a orientação argumentativa dos enunciados, estabelecendo, desta forma, as relações discursivas. Destacamos ainda que a classificação dos operadores argumentativos apresentada acima será utilizada na análise do nosso corpus.

\section{Os operadores argumentativos em anúncios publicitários: revendo alguns resultados}

Após apresentarmos a classificação dos operadores, discutiremos nesta subseção, alguns trabalhos sobre os operadores também apoiados na Semântica Argumentativa. Entre eles, inicialmente citamos o de Almeida (2001), que identificou, a partir de textos publicitários, que o comportamento argumentativo dos operadores argumentativos pode revelar os valores e os usos desses elementos em diferentes contextos. Tal hipótese é confirmada por meio do exemplo retirado do trabalho de Almeida:

(01) "Os ingleses são extremamente pontuais. Já os alemães preferem chegar um pouco mais cedo." (ALMEIDA, 2001, p.87)

No exemplo acima, o valor do "já" é semelhante ao de "mas", ou seja, contrapõe argumentos, introduzindo uma oposição semântica à enunciação anterior. Como sabemos, o operador "já" marca temporalidade, no entanto, aqui ele assume valor de oposição, comprovando a hipótese de que pode haver valores e usos diferentes dos operadores nesse tipo de enunciado.

Semelhante constatação pode ser entrevista nos resultados do artigo "O slogan publicitário: algumas estratégias argumentativas”, de Silva e Rigolon (2009), como evidencia o exemplo abaixo:

(02) Para uma pessoa ocupada como você, o tempo voa. Só que a gente pode voar ainda mais rápido. (SILVA, RIGOLON, 2009, p.4)

O uso da locução conjuntiva "só que", equivalendo ao "mas", introduz uma perspectiva que não é a do primeiro enunciador, mas a de outro enunciador (polifonia) para o qual o enunciado tende (o vôo mais rápido da Rio-Sul).

No estudo de Silva e Rigolon (2009), pudemos constatar ainda a presença de vários operadores também encontrados em nosso corpus. Por isso, a seguir, faremos uma sucinta análise dos pontos mais relevantes para a nossa pesquisa: 
A) O operador "ainda" (cf. ALMEIDA, 2001): Ducrot (1981) esclarece que este operador possui valor iterativo quando marca a repetição de um acontecimento; é continuativo quando marca a persistência de um estado. Segundo o autor, toda descrição semântica de um enunciado precedente deve nele reconhecer, entre outras coisas, duas indicações: o posto e o pressuposto. Todo enunciado do tipo $\mathbf{X}$ está ainda no estado $\mathbf{E}$ e no momento $\mathrm{t}$ indica simultaneamente ${ }^{6}$ :

(03) Leia voando este número. Você vai sentir ainda mais orgulho do Brasil. (p. 56)

O posto é que você sente orgulho do Brasil. Isso equivale a dizer que, após a leitura do anúncio, num momento ulterior $\mathbf{t}, \mathbf{X}$ não estará num estado $\mathbf{E}$; o pressuposto é de que o orgulho que você sente pelo Brasil será muito maior quando você vir os números que serão anunciados. Já na monografia de Pós-graduação de Santos (2007), temos uma visão bem abrangente desse operador, visto que em sua pesquisa ela trata apenas de dois operadores, o "ainda" e o "até". Em 19 casos com "ainda", presentes em seu trabalho, verificou-se que esse elemento pouco apareceu com a noção temporal, apenas dois casos foram encontrados, segue um deles como exemplo:

(04) Com mais de 3.000 agências, tem sempre uma perto de você. Se ainda não é cliente, abra a sua conta e conheça os benefícios de ser cliente do Bradesco.

Apesar de ter um predomínio da marca temporal, o "ainda" está servindo também como um marcador de contra-expectativa. O leitor, ao se deparar com o 'ainda', pode fazer a seguinte leitura: "Quase todos já são clientes desse banco e, por isso, podem aproveitar as vantagens oferecidas por ele. Sou um dos poucos que ainda não é cliente, não podendo, assim, usufruir os seus serviços, portanto, tenho também que me tornar cliente o quanto antes". O locutor direciona seus argumentos para as expectativas estabelecidas pelo interlocutor, os organiza de modo que ele mesmo as estabeleça no seu discurso, sendo as sentenças marcadas por ainda contrastivas em relação a essas expectativas.

B) O operador "só" e o operador "apenas" (cf. ALMEIDA, 2001): possui caráter argumentativo restritivo. O emprego pode denotar exclusão. "Só": esse elemento é responsável pela legitimidade do que está sendo veiculado. Exclui, afasta as outras marcas dos produtos concorrentes.

\footnotetext{
6 Para Ducrot, posto: X está no estado E em t (indicação já contida no enunciado antes da introdução de "ainda") pressuposto: Num momento ulterior t, X não estará no estado E.
} 
(05) Só uma marca é capaz de apagar todas as outras. Renew Intensive Line Minimizer. C) O operador "inclusive" (cf. ALMEIDA, 2001): o emprego desse operador está intimamente ligado à questão da ordem e da força dos argumentos na escala determinada por "r" e nos quais os operadores têm, como vimos, um papel fundamental, que é o de orientar argumentativamente o enunciado, instaurando, enfim, uma relação de ordem, segundo determinadas intenções no interior de uma escala argumentativa.

(06) "A Compaq respeita os direitos do consumidor. Inclusive o direito de escolha."

D) $O$ operador "e" (cf. ALMEIDA, 2001): a semântica formal caracteriza o "e" como um operador que se define por uma tabela de verdade que especifica que a conjunção de duas proposições, "p" e "q" é verdadeira, se e somente se "p" for verdadeira e "q" for verdadeira, todavia admite a hipótese de que haja diferenças entre o emprego dessa conjunção e " não só (...) mas também".

(07) "Siena bate o novo Corsa 16v. E não foi uma batida leve. O siena bateu e forte.

E) Os operadores "assim" e "afinal" (cf. ALMEIDA, 2001): O operador "assim" está no grupo de operadores que orientam os enunciados para determinado tipo de conclusão, uma ação que pretende sempre modificar o pensamento de outrem, coagindo-o. Estabelece uma relação entre uma oração antecedente e a consequente de forma tal que o que se diz na segunda é a conclusão do que se diz na primeira.

(08) (...) Assim em caso de roubo ou acidente com perda total, você recebe do seu seguro o que o seu carro vale no mercado. (O operador "afinal" introduz uma justificativa para o que foi dito anteriormente, levando a uma conclusão.)

(09) É só comparar. Afinal, congestionamento já basta o que você pega para ir trabalhar.

F) Os operadores de comparação (mais que, menor que, etc.) (cf. ALMEIDA, 2001): a comparação é estabelecida no ato da enunciação em uma escala em que os enunciados se dispõem numa relação de grau (mais fortes, menos fortes) que se presta menos à informação do que à argumentação, propriamente em favor de um julgamento. Na medida em que a comparação se apresenta como uma estrutura que, do ponto de vista argumentativo, contém dois movimentos contrários e simultâneos, um no sentido favorável e outro no sentido do desfavorável, pode-se dizer que existe entre os dois termos comparados uma espécie de oposição que, semanticamente, poderia ser identificada como uma negação da propriedade, que um dos termos absorve em desfavor do outro. (VOGT, 1977:89) 
Almeida (2001) distribui ainda, complementando a descrição feita acima, os operadores argumentativos em três faixas, quanto a sua frequência em textos publicitários:

\section{Tabela III: Frequência dos operadores argumentativos}

\begin{tabular}{|c|c|c|}
\hline Alta frequência & Frequência média & Baixa frequência \\
\hline $\begin{array}{l}\text { até, até mesmo, ainda, o/a } \\
\text { melhor, mas, também, só, } \\
\text { somente (na pesquisa de } \\
\text { Almeida, } 131 \text { ocorrências ou } \\
32,27 \% \text { do total) }\end{array}$ & $\begin{array}{l}\text { nem, já, além de/do, apenas, } \\
\text { ou, mesmo (a), se, e, então, } \\
\text { porque (na pesquisa de } \\
\text { Almeida, } 128 \text { ocorrências ou } \\
31,53 \% \text { do total) }\end{array}$ & $\begin{array}{l}\text { inclusive, como, afinal, tão/tanto } \\
\text { que, (mais) do que, por } \\
\text { exemplo, pouco, um pouco, } \\
\text { mais um pouco, já/agora, enfim, } \\
\text { aliás, ou seja, quanto } \\
\text { mais/maior, aqui, além disso, } \\
\text { em outras palavras, assim, na } \\
\text { verdade, daí (aí), menor/muito } \\
\text { menor, apesar que, desde que, } \\
\text { quer dizer, portanto, tão/quanto, } \\
\text { ao invés de, ora, mais um } \\
\text { pouquinho, quase, por mais } \\
\text { que, mesmo que, ou melhor, } \\
\text { logo, ali, de certo modo, com } \\
\text { certeza, aliás, lá, é que, pelo } \\
\text { menos, mas também, } \\
\text { finalmente, necessariamente, } \\
\text { certamente, altamente, } \\
\text { seguramente, naturalmente, } \\
\text { definitivamente, simplesmente, } \\
\text { absurdamente, } \\
\text { exageradamente. (na pesquisa } \\
\text { de Almeida, } 147 \text { ocorrências ou } \\
\text { 36,20\% do total). }\end{array}$ \\
\hline
\end{tabular}

Fonte: adaptado de Almeida (2001)

Por fim, em suas considerações finais, Almeida levanta a questão de não se priorizar na gramática tradicional, o estudo da linguagem e dos elementos abordados durante a pesquisa. A autora questiona se não seria essa uma postura de caráter ideológico. Questiona, ainda, se a exploração mecânica dos operadores, sem uma reflexão sobre o seu uso, a análise apenas superficial com relação à natureza do texto e o não conhecimento das peculiaridades do discurso e sua ideologia subjacente não se dariam em função do objetivo de tentar privar o cidadão de um posicionamento crítico frente ao discurso produzido pela mídia. Ela não responde a essas questões, mas deixa esses questionamentos passíveis de serem estudados posteriormente.

Já Santos (2007) buscou realizar um estudo que demonstrasse o quão produtivos são os usos de ainda e até nos anúncios publicitários atuais com funções mais discursivas, fato que ficou comprovado, tendo em vista o maior número de casos 
encontrados como argumentativos (74\% e $62 \%$, respectivamente) e poucos com usos mais adverbiais ou funcionando apenas como preposição.

O trabalho de Silva e Rigolon (2009), por sua vez, chega à conclusão de que o sujeito da enunciação articula o seu discurso de modo a prevalecer a sua fala, utilizandose de modalizadores, operadores argumentativos e indicadores atitudinais que marcam as intenções do locutor que, embora introduza nos enunciados estratégias de caráter polifônico, restringe as possibilidades do enunciatário.

\section{Análise dos dados}

\subsection{Frequência dos Operadores argumentativos}

Ao selecionarmos os operadores argumentativos encontrados nos anúncios publicitários que constituem o nosso corpus, obtivemos os seguintes resultados:

Tabela IV: Levantamento dos operadores argumentativos

\begin{tabular}{|c|c|}
\hline $\begin{array}{c}\text { OPERADOR } \\
\text { ARGUMENTATIVO }\end{array}$ & $\begin{array}{c}\text { NÚMERO DE OCORRËNCIAS } \\
\mathbf{N}^{\mathbf{0}} / \%\end{array}$ \\
\hline E & $6 / 17,14 \%$ \\
\hline Mas & $4 / 11,42 \%$ \\
\hline Só & $3 / 8,57 \%$ \\
\hline Agora & $3 / 8,57 \%$ \\
\hline Mais & $2 / 5,71 \%$ \\
\hline Inclusive & $2 / 5,71 \%$ \\
\hline Também & $2 / 5,71 \%$ \\
\hline Apenas & $1 / 2,85 \%$ \\
\hline Que & $1 / 2,85 \%$ \\
\hline Menos (do) que & $1 / 2,85 \%$ \\
\hline Já & $1 / 2,85 \%$ \\
\hline Assim & $1 / 2,85 \%$ \\
\hline Afinal & $1 / 2,85 \%$ \\
\hline Hoje & $1 / 2,85 \%$ \\
\hline Ainda & $1 / 2,85 \%$ \\
\hline Mais que & $1 / 2,85 \%$ \\
\hline E só & $1 / 2,85 \%$ \\
\hline Mesmo & $1 / 2,85 \%$ \\
\hline A mais & $1 / 2,85 \%$ \\
\hline O melhor & $1 / 2,85 \%$ \\
\hline TOTAL & $35 / 100 \%$ \\
\hline
\end{tabular}


Em uma análise quantitativa da Tabela IV, podemos observar a predominância, nos anúncios publicitários da revista on-line Veja, dos operadores "e" e "mas", seguidos dos operadores "só" e "agora". O que notamos, no entanto, foi que os valores de cada operador, mudam de acordo com o anúncio em que está sendo empregado.

Em comparação com os resultados apontados por Almeida (2001), notamos que os operadores "mas" e "só" estão entre os que a pesquisadora classificou como de alta frequência, no entanto, o mesmo não acontece com o "e" e o "agora". Interessante notar que esse último operador ficou em 3ำ lugar na nossa frequência, assim como o operador "só", e foi classificado como de baixa frequência no trabalho supracitado.

\subsection{Análise dos dados: tipos de operadores argumentativos}

Como mencionado, após selecionarmos as ocorrências dos operadores argumentativos, apresentamos a seguir os tipos de operadores argumentativos conforme classificação de Koch (2006), baseada em Ducrot e consequentemente, os valores semânticos mais empregados nos anúncios publicitários analisados.

TabelaV $V^{7}$ : Tipos de operadores argumentativos e sua frequência

\begin{tabular}{|c|c|c|}
\hline $\begin{array}{c}\text { TIPO DE } \\
\text { OPERADOR }\end{array}$ & $\begin{array}{c}\text { Frequência } \\
\text { (no de } \\
\text { ocorrências) }\end{array}$ & Frequência (\%) \\
\hline TIPO A & 3 & $8,33 \%$ \\
\hline TIPO B & 13 & $36,11 \%$ \\
\hline TIPO C & 1 & $2,77 \%$ \\
\hline TIPO D & 0 & $0 \%$ \\
\hline TIPO E & 4 & $11,11 \%$ \\
\hline TIPO F & 2 & $5,55 \%$ \\
\hline TIPO G & 2 & $5,55 \%$ \\
\hline TIPO H & 6 & $16,66 \%$ \\
\hline TIPO I & 5 & $13,88 \%$ \\
\hline TOTAL & $\mathbf{3 6}$ & $\mathbf{1 0 0} \%$ \\
\hline
\end{tabular}

Tabela $\mathrm{VI}^{8}$ : Distribuição dos operadores argumentativos de acordo com os tipos propostos

\begin{tabular}{|c|c|c|c|}
\hline $\begin{array}{c}\text { TIPO DE } \\
\text { OPERADOR }\end{array}$ & $\begin{array}{c}\text { OPERADO } \\
\mathbf{R} \\
\text { ARGUME }\end{array}$ & FREQUÉNCIA (No) & Frequência (\%) \\
\hline \multirow{2}{*}{ TIPO A } & Mesmo & 1 & $2,77 \%$ \\
\cline { 2 - 4 } & Inclusive & 2 & $5,55 \%$ \\
\hline
\end{tabular}

Conferir classificação apresentada, segundo Koch (2006), na 2.2. (Os operadores argumentativos), deste artigo. 


\begin{tabular}{|c|c|c|c|}
\hline \multirow{4}{*}{ TIPO B } & Mas & 2 & $5,55 \%$ \\
\hline & $E$ & 7 & $19,44 \%$ \\
\hline & Mais & 2 & $5,55 \%$ \\
\hline & Também & 2 & $5,55 \%$ \\
\hline TIPO C & Assim & 1 & $2,77 \%$ \\
\hline TIPO D & - & - & - \\
\hline \multirow{4}{*}{ TIPO E } & Mais que & 1 & $2,77 \%$ \\
\hline & O melhor & 1 & $2,77 \%$ \\
\hline & A mais & 1 & $2,77 \%$ \\
\hline & Menos & 1 & $2,77 \%$ \\
\hline \multirow[t]{2}{*}{ TIPO F } & Que & 1 & $2,77 \%$ \\
\hline & Afinal & 1 & $2,77 \%$ \\
\hline TIPO G & Mas & 2 & $5,55 \%$ \\
\hline \multirow[t]{4}{*}{ TIPO H } & Ainda & 1 & $2,77 \%$ \\
\hline & Hoje & 1 & $2,77 \%$ \\
\hline & Já & 1 & $2,77 \%$ \\
\hline & Agora & 3 & $8,33 \%$ \\
\hline \multirow[t]{2}{*}{ TIPO I } & Só & 4 & $11,11 \%$ \\
\hline & Apenas & 1 & $2,77 \%$ \\
\hline TOTAL & \multicolumn{2}{|c|}{$36^{9}$} & $100 \%$ \\
\hline
\end{tabular}

As Tabelas V e VI apontam que os operadores do tipo $b$ - que somam argumentos $a$ favor de uma mesma conclusão - foram os que mais apareceram nos anúncios. Encontramos nesse grupo os operadores: mas, e, mais e também. Nesse primeiro tipo analisado, percebemos que alguns desses operadores são tipicamente utilizados para acrescentar argumentos, como o e o também, enquanto que o mas e mais, apesar de não exercerem tipicamente essa função, aparecem nos anúncios com esse valor:

(10) Quer fazer uma viagem, mas não sabe por onde começar? Chegou o novo viageaqui. $\underline{\mathrm{O} \text { melhor }}$ lugar para te inspirar, planejar e compartilhar sua viagem. (viageaqui.com.br)

O operador mas não opõem ideias nesse anúncio, ao contrário, acrescenta elementos, podendo ser substituído por e ("Quer fazer uma viagem e não sabe por onde começar?”). Em outro exemplo, o operador mas, apareceu, entretanto, exercendo a função de contrapor argumentos, como podemos ver em um dos exemplos:

(11) O Boticário. A vida é bonita, mas pode ser linda.

Podemos perceber que o trabalho com a argumentatividade nesse anúncio, vai além do objeto de estudo desse trabalho. Nesse fragmento (11), o anunciante lança primeiro o 
nome da marca, apresenta o argumento mais fraco para depois contrapor a ideia com o uso do mas, indicando que: para a vida ser linda basta usar $O$ Boticário.

Outro operador argumentativo que merece destaque é o e. Nos anúncios analisados, esse operador exerceu sua função principal de somar argumentos a favor de uma conclusão. O que observamos, porém, é que além de somar argumentos, ora ele enfatiza o último argumento, ora apenas acrescenta outro argumento numa mesma escala, ou ainda apresenta um argumento decisivo levando a determinada conclusão:

(12) Queijo agora tem nome, tem sabor e tem S de Sadia. (Queijo Sadia)

(13) O Palio mudou. E como mudou. (Novo Palio-FIAT)

(14) Nobre seguradora do Brasil S.A .: Tradição e inovação conquistando lideranças. (Nobre Seguradora do Brasil)

O exemplo (12), ao acrescentar o nome da marca do queijo, já consolidada no mercado, traz o argumento mais forte, que é decisivo para persuadir o consumidor na compra do produto.

Já no exemplo (13) temos mais uma ênfase que um acréscimo, ao repetir o verbo "mudar" é como se dissesse que o Palio mudou muito, tem-se, assim, uma intensificação e não apenas uma adição.

É nítida, no último anúncio, inclusive no nível sintático, a coordenação dos argumentos "tradição" e "inovação". Pensando no sentido quase oposto dos dois substantivos coordenados pelo operador e, nota-se que uma empresa que consegue 0 equilíbrio entre a tradição e a inovação só pode estar à frente das demais. A estratégia de unir dois elementos contrários numa mesma escala por meio de um operador que tem por função somar argumentos pode parecer contraditória, mas consegue oferecer dois argumentos essenciais, de modo sutil.

Os operadores do tipo $h$ foram os segundos que mais apareceram nos anúncios analisados. Nesse grupo estão presentes em nosso corpus os operadores ainda, hoje, já e agora. Esses operadores têm a função de introduzir no enunciado conteúdos pressupostos, estabelecendo sentidos que envolvem o "antes" e o "depois" de determinada ação, no nosso caso, a ação da entrada do produto no mercado. Vejamos alguns exemplos que ilustram essa situação:

(15) A educação e o carinho que o seu filho recebe em sua casa, agora também na escola. (Sistema Maxi de ensino) 
(16) "De Goiás, fomos para Brasília. De lá para todo o Brasil. E hoje alimentamos famílias no mundo inteiro. José Batista Sobrinho, o "Zé Mineiro". Fundador da marca Friboi e da JBS. (Friboi - empresa produtora de carnes)

Note-se que em ambos os exemplos, os operadores argumentativos agora e hoje, deixam de ser simples marcadores temporais, como vimos nas gramáticas, para também atribuir força ao segundo argumento, que passa a ser decisivo. Uma possível releitura do primeiro exemplo seria: "As escolas não ofereciam o tratamento que as crianças têm em suas casas, mas com o Sistema Maxi de ensino elas passam a ter esse tratamento". Veja que tudo que vem antes do "agora" ganha força a favor do produto anunciado, é delimitado o que acontece antes e depois da chegada do novo produto.

Segundo Ducrot, citado por Ameida (2001, p.56): "Todo enunciado do tipo X está ainda no estado $\mathrm{E}$ e no momento $\mathrm{t}$ indica simultaneamente: posto: $\mathrm{X}$ está no estado $\mathrm{E}$ em t (indicação já contida no enunciado antes da introdução de "ainda") pressuposto:

Num momento ulterior $\mathbf{t}$, $\mathbf{X}$ não estará no estado E." Assim ocorre também no segundo exemplo, o qual mostra a expansão do produto da Friboi. O que observamos é que tanto o agora como o hoje não deixam totalmente de exercer sua função de marcador temporal, o que ocorre, no entanto, é um acréscimo de funções, ao mesmo tempo em que marcam o tempo anterior e posterior a algo, situam o produto numa zona privilegiada, há um antes e um depois de o produto chegar ao mercado.

Um dos operadores analisados que mais nos chamou a atenção foi o operador só. Ele foi inserido na tabela como sendo do tipo $i$ - operadores que se distribuem em escalas opostas, um deles funcionando numa escala orientada para a afirmação total e o outro, para a negação total. Nesse grupo encontramos também o operador apenas. Enquanto esse último operador exerce fidedignamente o papel indicado na classificação proposta por Koch (2006), o operador só apresenta um caráter de restrição e até exclusão, como podemos ver nos anúncios que se seguem:

(30) Sobre a receita de Heineken temos só três coisas a dizer: Malte, lúpulo e água. (Cerveja Heineken)

(31) Só há desenvolvimento com respeito ao meio ambiente e às pessoas. E só uma empresa que sabe disto poderia estar listada, pela quinta vez consecutiva no índice de Sustentabilidade Empresarial da Bovespa. (Eletrobrás - empresa brasileira de energia elétrica) 
Se seguíssemos, no exemplo (30), a leitura proposta por Koch(2006), correríamos o risco de ter um argumento contra o produto, visto que, os argumentos elencados (malte, lúpulo e água) estariam numa escala de negação total, seria como se a marca Heineken oferecesse pouco comparado a outras marcas. O que acontece aqui, entretanto, é um efeito de restrição, a marca se restringe a caracterizar a cerveja no que ela tem de mais básico, o que formaria uma cerveja pura, porém de qualidade. Conclui-se, dessa forma, que a Heineken não precisaria de mais que o básico da cerveja, enquanto as outras marcas precisariam de acrescentar ingredientes especiais a fim de se tornarem atrativas e diferenciadas.

Já o exemplo (31) expõe, logo de início, a ideia de restrição quando diz que "só há desenvolvimento com respeito ao meio ambiente e às pessoas", ou seja, as empresas que não respeitam o meio ambiente e às pessoas são consideradas empresas subdesenvolvidas. Ao inserir o segundo argumento "E só uma...da Bovespa" ele exclui todas as demais empresas, já que, por uma questão de lógica, a empresa listada pela quinta vez consecutiva no índice de Sustentabilidade Empresarial da Bovespa, só pode ser a Eletrobrás.

Os operadores argumentativos que estabelecem relações de comparação entre elementos, visando a uma determinada conclusão (tipo e) também foram encontrados em grande número nos anúncios analisados. Identificamos os operadores mais que, o melhor, a mais e menos do que. A relação de comparação entre os elementos subjaz uma relação de restrição e exclusão, visto que, ao comparar o produto anunciado com outros, o que o operador argumentativo faz é direcionar toda a força argumentativa para esse produto, excluindo todos os demais. Analisemos um desses casos:

(32) A vida pede mais que um banco. Pede parceria, cuidado, satisfação (Caixa Econômica Federal)

A publicidade, por ser riquíssima em recursos argumentativos, outra vez nos traz um anúncio que ultrapassa os limites do proposto nesse trabalho. Falo aqui da relação pragmática, que o substantivo "banco" traz consigo. A Caixa Econômica Federal - CEF tem, por diversos motivos, inclusive históricos, a particularidade de ser chamada de Caixa e não de Banco. Sendo assim, ao inserir o primeiro argumento "a vida pede mais que um banco", a CEF automaticamente se exclui desse grupo. Sabiamente, o segundo argumento "a vida pede parceria, cuidado, satisfação" a inclui como única empresa capaz 
de oferecer esse conjunto de atributos, justamente pelo fato de a empresa em questão não se tratar de um banco. Novamente, a lógica nos faz chegar a essa conclusão, por meio da orientação dos operadores argumentativos.

Para finalizar, apresentamos a análise do operador inclusive encontrado em nosso corpus, como um operador classificado como do tipo a - operadores que assinalam o argumento mais forte dentro de uma escala que direciona para determinada conclusão. A título de ilustração, vejamos um anúncio em que esse operador aparece:

(34) Qualidade, serviços, atendimento, entrega. Tudo que o brasileiro quer, a Casas Bahia tem. Inclusive os melhores preços. (Casas Bahia - Rede de lojas de móveis e eletrodomésticos)

Tomando como parâmetro, o esquema feito por Koch (2006, p.31), podemos representar essa escala argumentativa da seguinte maneira:

$\mathrm{R}^{10}:: \mathrm{A}$ Casas Bahia tem tudo que o brasileiro quer.

(arg. + forte)

Como podemos evidenciar com a ilustração acima, o operador argumentativo inclusive apresenta o argumento principal e final, inserindo um dos principais argumentos em que o consumidor está interessado: o preço. Mas, antes disso, o anúncio elenca diversas características que uma boa empresa deve ter, resumido explicitamente em: "Tudo que o brasileiro quer, a Casas Bahia tem".

Enfim, pudemos notar neste artigo, que os operadores argumentativos encontrados em nosso corpus exercem, na maioria das vezes, sua função principal, conforme a classificação que utilizamos, proposta por Koch. No entanto, encontramos algumas peculiaridades, como por exemplo, o operador "mas", ao exercer função somativa e o 
operador "só", função restritiva. O importante é que, independentemente, da função exercida nos anúncios, esses operadores não deixaram, em nenhum momento, de cumprir sua função argumentativa, foco de nossa investigação.

\section{Considerações finais}

Os operadores argumentativos, como pudemos evidenciar ao longo deste artigo, são elementos linguísticos que fornecem informações e, ao mesmo tempo, funcionam como instrumentos de argumentação do enunciador, evidenciando a poderosa força que eles transmitem. Entretanto, observamos, ao consultar algumas gramáticas normativas que os operadores, em alguns casos, são considerados como elementos meramente relacionais, ou seja, em um nível linguístico, são denominados conectivos (conjunções) que têm apenas a função de ligar orações. É a Semântica Argumentativa, que vai recuperar esses elementos, por serem justamente eles que determinam o valor persuasivo dos enunciados.

Assim, com base num corpus composto por esse gênero textual (anúncios), buscamos, com este trabalho, investigar quais os operadores argumentativos mais frequentes e quais os valores semânticos associados a eles quando empregados em anúncios publicitários contemporâneos publicados em uma revista de âmbito nacional (Veja).

Vale destacar que Koch (2008) afirma que dentro da dimensão argumentativa da linguagem, está inserida uma classe de palavras, rotuladas de operadores argumentativos, itens lexicais que estão presentes tanto nos textos escritos, quanto nos orais, pois em todo texto subjaz uma carga de sentido que expressa a intencionalidade de seu autor; intencionalidade que é desvendada, progressivamente, através de pistas que os operadores argumentativos podem sinalizar.

Assim, observamos que alguns operadores argumentativos exerceram em alguns anúncios, valores diferentes se comparados entre si, enquanto outros operadores tiveram sempre o mesmo comportamento, por exemplo, o operador argumentativo "mas", ora contrapôs argumentos, ora somou argumentos a favor de uma mesma conclusão, assumindo o valor do operador argumentativo "e". O operador "e", por sua vez, manteve em todos os anúncios analisados, o valor de um operador que acrescenta argumentos para uma mesma conclusão. 
Por fim, pudemos observar que os operadores argumentativos, apesar de, muitas vezes, no ensino das escolas, ainda ficar em um plano secundário, limitado apenas a uma atividade de "decorar", sua má compreensão pode levar a dificuldade de compreensão do texto, já que grande parte da força argumentativa está alicerçada nessas marcas linguísticas. O mesmo se dá ao produzir um texto, seja ele oral ou escrito, pois, se a linguagem é eminentemente persuasiva, convencer o outro do meu ponto de vista passa a ser essencial desde a mais tenra idade, passando a ser também imprescindível conhecer e saber manusear os recursos para que se isso realize.

\section{Referências}

ALMEIDA, Lucimar. Análise semântica de operadores argumentativos em textos publicitários.2001. 187 fls. (dissertação de mestrado em Linguística) Universidade Federal de Uberlândia, 2001.

BECHARA, E. Moderna Gramática portuguesa. 38. ed. rev. e amp. 19a reimp. Rio de Janeiro: Lucerna, 2005.

CEGALLA, D. P. Novíssima gramática da língua portuguesa. 48.ed. rev. São Paulo: Companhia Editora Nacional, 2008.

CUNHA, Celso \& CINTRA, Lindley. Nova gramática do português contemporâneo. 3.ed. Rio de Janeiro: Nova Fronteira, 2001.

DUCROT, Oswald. O dizer e o dito. Rev. Téc. Trad. GUIMARÃES, E. Campinas, SP: Pontes, 1987.

KOCH, Ingedore. A coesão textual. $21^{\underline{a}}$ ed. São Paulo: Contexto, 2008.

$\mathrm{KOCH}$, Ingedore. A interação pela linguagem. 10ª ed. São Paulo: Contexto, 2006.

KOCH, Ingedore. Argumentação e linguagem. 11 ${ }^{\text {a }}$ ed. São Paulo: Cortez, 2008.

LARA, Gláucia. O uso dos operadores argumentativos em textos publicitários. In: Anais da 10를 Conferência Internacional de Pragmática. Göteborg, Suécia, 2007.

MARCUSCHI, Luiz Antônio. Produção textual, análise de gêneros e compreensão. São Paulo: Parábola Editorial, 2008.

NEVES, Maria Helena. Gramática de Usos do Português. 2 ed. São Paulo: EDUNESP, 2011.

SANTOS, Evelyn. Análise semântico-discursiva de ainda e até em anúncios publicitários. Monografia de Pós-graduação em Letras Vernáculas - UFRJ, 2007. 
SILVA, Edson \& RIGOLON, Wilma. O slogan publicitário: algumas estratégias argumentativas. Revista Online de Comunicação, Linguagem e Mídias. RUMORES, Vol. 2, № 2 (2009). Edição 4 - Janeiro-Abril de 2009.

VASCONCELOS, Marilda. Discurso publicitário: ação, paixão e cognição. 2007. Tese de doutorado em Língua Portuguesa. PUC-SP, 2007.

VEJA. Disponível em: <http://veja.abril.com.br/acervodigital/home.aspx>. Acesso em jan de 2012. 


\section{Anexos: corpus utilizado ${ }^{11}$}

Anúncios da Revista Veja online, veiculados de outubro de 2011 a fevereiro de 2012

1. A caixa tem uma rede de atendimento que cobre todo o Brasil. Mas a vida pede mais. (Caixa Econômica Federal)

2. A OGX acaba de alcançar um marco histórico: $O$ início da produção de petróleo no Brasil por uma empresa privada brasileira. A conquista é grande, mas o orgulho é ainda maior. (OGX - empresa privada petrolífera brasileira)

Edição 2255 de 8 de fevereiro de 2012. Acesso em 14 de fevereiro de 2012 às 16:00.

3. Queijo agora tem nome, tem sabor $\underline{e}$ tem $S$ de Sadia. (Queijo Sadia)

4. Um aplicativo que fala o que está acontecendo no mundo, a previsão do tempo, cotações da Bolsa e a sua agenda do dia. EE é verdade, fala mesmo. (Aplicativo 24 horas Veja.com para Ipad.)

Edição 2254 de $1^{\circ}$ de fevereiro de 2012. Acesso em 14 de fevereiro de2012 às 16:33.

5. A vida pede mais que um banco. Pede parceria, cuidado, satisfação (Caixa Econômica Federal)

6. Sobre a receita de Heineken temos só três coisas a dizer: Malte, lúpulo e água. (Cerveja Heineken)

7. O JC digital tem notícias atualizadas, galerias de fotos e vídeos. E é o primeiro. (Jornal do comércio - Pernambuco)

Edição 2253 de 25 de janeiro de 2012. Acesso em 14 de fevereiro de 2012 às 17:21.

8. Quer fazer uma viagem, mas não sabe por onde começar? Chegou o novo

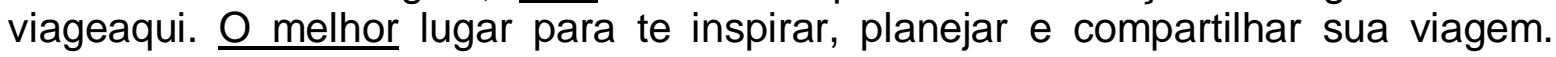
(viageaqui.com.br)

Edição 2251 de 11 de janeiro de 2012. Acesso em 16 de fevereiro de 2012, às 14:44.

9. O Boticário. A vida é bonita, mas pode ser linda. (O Boticário)

Edição 2250 de 04 de janeiro de 2012. Acesso em 16 de fevereiro de 2012, às 17:22.

10.CVC. A empresa de turismo mais conhecida do Brasil. E a mais reconhecida também. (CVC - empresa de turismo)

11. O Palio mudou. E como mudou. (Novo Palio-FIAT)

12. Nobre seguradora do Brasil S.A .: Tradição e inovação conquistando lideranças. (Nobre Seguradora do Brasil)

13. Só há desenvolvimento com respeito ao meio ambiente e às pessoas. E só uma empresa que sabe disto poderia estar listada, pela quinta vez consecutiva no índice de Sustentabilidade Empresarial da Bovespa. (Eletrobrás - empresa brasileira de energia elétrica)

Edição 2249 de 28 de dezembro de 2011. Acesso em 17 de fevereiro de 2012, às 17:11.

14. "De Goiás, fomos para Brasília. De lá para todo o Brasil. E hoje alimentamos famílias no mundo inteiro. José Batista Sobrinho, o "Zé Mineiro". Fundador da marca Friboi e da JBS. (Friboi - empresa produtora de carnes)

Edição 2249 de 28 de dezembro de 2011. Acesso em 16 de fevereiro de 2012, às 17:43.

15. Qualidade, serviços, atendimento, entrega. Tudo que o brasileiro quer, a Casas Bahia tem. Inclusive os melhores preços. (Casas Bahia - Rede de lojas de móveis e eletrodomésticos)

11 Todos os anúncios foram extraídos de: http://veja.abril.com.br/acervodigital/home.aspx. 
Edição 2247 de 10 de dezembro de 2011. p. 178-179. Acesso em 01 de março de 2012, às 17:06.

16. Novos cremes de tratamento anticaspa head \& shoulders. Couro cabeludo saudável e cabelo maravilhoso em apenas 1 minuto. (Head \& Shoulders - linha de )

Edição 2247 de 10 de dezembro de 2011. pag. 55. Acesso em 02 de março de 2012, às 10:36.

17. Nosso clientes poderiam escolher qualquer banco para trabalhar. Nosso objetivo é só mostrar que eles acertaram. (Banco Itaú)

Edição 2247 de 10 de dezembro de 2011. pag. 56-57. Acesso em 02 de março de 2012, às 10:38.

18.Sonhar não custa nada. Realizar custa menos do que você imagina. (Consórcio Nacional Chevrolet)

Edição 2247 de 10 de dezembro de 2011. pag.101. Acesso em 02 de março de 2012, às $10: 42$.

19.O Tiggo é tão completo que vem com mais um item de série: Fábrica no Brasil. Por $\mathrm{R} \$ 52990,00$, a chave já está na sua mão. (Modelo de veículo da marca Chery)

Edição 2245 de 30 de novembro de 2011. pag. 95. Acesso em 02 de março de 2012, às 11:04.

20. "Todos os dias tomo decisões que garantem a origem dos produtos Friboi para milhares de famílias. Inclusive para a minha". (Fala de José Luiz Medeiros - diretor de originação - colaborador desde 1984. )

Edição 2245 de 30 de novembro de 2011. pag. 110. Acesso em 02 de março de 2012, às 11:07.

21. A educação e o carinho que o seu filho recebe em sua casa, agora também na escola. (Sistema Maxi de ensino)

Edição 2244 de 23 de novembro de 2011. Acesso em 02 de março de 2012, às 11:20.

22. Brincar ou aprender? No Anglo é assim: brincar e aprender!

23. Chegou Nissan March. Agora todo mundo pode ter um carro japonês.

Edição 2242 de 9 de novembro de 2011. Acesso em 24 de março de 2012.

24. Não é à toa que Sundown é Top of mind: afinal, a vida gira em torno do sol.

Edição 2241, de 02 de novembro de 2011. Acesso em 21 de abril de 2012, às 17:20.

25. Novo Santafé 2012. Agora com novas rodas, nova frente, nova traseira e novo sistema de controle de declive. (carro da Hyundai)

Edição 2240 de 26 de outubro de 2010. p. 25. Acesso em 21 de abril de 2012, às 17:27. 